\title{
Well testing/Well Design in CBM wells
}

\author{
C. Paveley (Eclipse Petroleum Technology Limited)
}

\section{SUMMARY}

There are a number of completion options available for successful development of CBM. A number of design factors, with field examples, will be presented in this paper as follows:

- a comparison of the performance of horizontal wells with vertical wells; covering the effects of wellbore length, skin factor and coal seam thickness on performance.

- the importance of wellbore diameter and geometry and their impact directly on wellbore stability (loss of well/laterals) and production (ability to lift liquids).

- the effectiveness of cavity and under-reaming completions compared to fractured wells.

Many CBM wells/formations do not flow prior to testing leading to difficulties in well test design. General guidelines for injection/fall off testing will be presented together with some of the common pitfalls. 